\title{
EVALUATION OF ROOT CANAL CONFIGURATION OF PERMANENT MANDIBULAR ANTERIOR TEETH IN EGYPTIAN SUBPOPULATION: A CONE BEAM COMPUTED TOMOGRAPHY STUDY
}

\author{
Soha Basha*
}

\begin{abstract}
Cone beam computed tomography (CBCT) affords high-quality image with a relatively low radiation doses and low costs. It is considered as a valuable tool in endodontic field as it determines root morphology, number of roots, canals and accessory canals. The aim of the present study was to evaluate the permanent mandibular anterior teeth canal morphology in Egyptian subpopulation.

Materials and Methods: A total of 100 patients were enrolled in this study and were assigned in two groups (50 females and 50 males). In each group centrals, laterals and canines of both sides were examined (100 centrals, 100 laterals and 100 canines). CBCT Images were obtained using J Morita CBCT unit and canals were categorized into the five types of Vertucci's classification. The observer evaluated the images twice with one-week interval between assessments.
\end{abstract}

Results: Type I Vertucci configuration was the most prevalent configuration in our sample and the incidence of this type was slightly higher in female than male samples. Furthermore, type III and V Vertucci configuration were slightly more in males than females.

Conclusion: In the present study it was concluded that the root and root canal morphology of Egyptian subpopulation was, in general, comparable to that of other populations and that the incidence of canal variations might occur as a result of ethnicity more than gender.

KEY WORDS: Apical foramen, CBCT, Root canal configuration, Vertucci

\section{INTRODUCTION}

Cone beam computed tomography

(CBCT) provides high-quality image that has very valuable diagnostic information by means of a relatively low radiation doses and low costs. ${ }^{1}$ It gives a threedimensional (3D) presentation of 3D images of the individual tooth or dentition in relation to the surrounding skeletal tissues. ${ }^{2}$ CBCT offers various advantages compared to the traditional two-dimensional (2D) radiography, including a lack of superimposition and geometric distortions, 3D display and relatively low ionizing radiation comparing to the amount of data provided. CBCT

* Oral Medicine, Periodontology And Radiology Department, Faculty Of Dentistry/ Pharos University In Alexandria, Egypt. 
supplies the clinician with an accurate detailed diagnostic data which directly influence the clinical decisions and facilitate selection of accurate treatment plan which grants a good prognosis. ${ }^{3}$ Thus, CBCT is widely used in various dental disciplines including implantology, endodontics, periodontology, maxillofacial surgery and orthodontics. $^{4}$

CBCT is a very useful tool in endodontic field as it determines root morphology, number of roots, canals and accessory canals, as well as establishing working length and angulations of roots and canals. Consequently, it is considered to be a superior preoperative assessment method.

In order to achieve proper endodontic treatment, the clinician should be absolutely acquainted with canal anatomy and morphology. Besides, the clinician should have thorough knowledge concerning the anatomy of the root canal system and the different anatomical variations. ${ }^{5}$

Canal configuration and root anatomy is genetically determined and may vary significantly with ethnicity, race and sex. ${ }^{6}$ Consequently there are similarities as well as variations in the patterns of root canal configuration among different populations. These variations are important for anthropological science and forensic issues.

Root canal treatment is performed frequently for mandibular anterior teeth. During endodontic treatment the dentist facing some difficulty because these teeth have a narrow crown which causes restricted access to the root canals. ${ }^{7}$ The initial belief was that mandibular incisors generally have single root canal with a coronally oval shape that gradually becomes narrower bucco-lingually at mid-root. However, recent studies revealed high variation of root canal morphology among mandibular anterior teeth. ${ }^{8,9}$

Mandibular canines, similar to mandibular incisors, have a root wider bucco-lingually than mesio-distally. Many studies reported that these teeth infrequently have two or more roots or canals. ${ }^{9,10}$

Several studies have investigated root canal morphology using various diagnostic methods..$^{11,12}$ These methods include polyester resin impressions, creating transparent samples and taking radiographs in the mesiodistal and/or buccolingual directions. ${ }^{13}$ Currently the main method that gives detailed information about the morphology of roots and their variations is CBCT.

Many authors discussed the accuracy of CBCT in detecting various endodontic conditions including the presence of additional canals, their shape and curvature, apical periodontitis, root fracture and root resorption. Conventional radiographs provide little or no information about these data. On the other hand, CBCT imaging can reveal the same findings with high accuracy. ${ }^{14}$

Owing to the reliability and accuracy of CBCT, our study was conducted to evaluate the permanent mandibular anterior teeth canal morphology in Egyptian subpopulation.

\section{MATERIALS AND METHODS:}

This retrospective study was approved by the Ethical Review Board of the Faculty of Dentistry Pharos University in Alexandria. The images were taken mainly for diagnosis and treatment planning for patients requiring orthodontic treatment, placement of dental implants or localization of impacted teeth. Informed consent was routinely obtained from all patients before clinical and radiographic examinations.

The study was conducted for a total of 100 patients (50 females and 50 males) with age between 15-60 years who visited the outpatient clinic from September 2016 till September 2017. The male and female patients were assigned into two groups and in each group centrals, laterals and canines of both 
sides were examined (100 centrals, 100 laterals and 100 canines).

The evaluation was done to the mandibular permanent anterior teeth. The following criteria were excluded from our study: teeth with immature apices, apical periodontitis, root canal fillings, and post and crown restorations.

Canals were categorized into five types of Vertucci's classification ${ }^{15}$ as follows:

- Type I: A single canal is present from the pulp chamber to the apex.

- Type II: Two separate canals leave the pulp chamber, but join to form one canal to the site of exiting.

- Type III: One canal leaves the pulp chamber, divides into two within the root, and then merge to exit in one canal.

- Type IV: Two separate and distinct canals are present from the pulp chamber to the apex.

- Type V: Single canal leaving the pulp chamber but dividing into two separate canals with two separate apical foramina.

Images were obtained using J Morita CBCT unit (J. Morita, Corporation, Kyoto, Japan), Imaging Software Included i-Dixel 2.0 Software operated at $84 \mathrm{kVp}$ and 9-14 $\mathrm{mA}$ with a voxel size of 0.16 $\mathrm{mm}$, exposure time of 6 seconds, and field of view of $80 \times 100 \mathrm{~mm}$.

Images were including 400 permanent mandibular incisors and 200 mandibular canines. All CBCT images were of good quality and free of artifacts. The following observations were recorded: Number of roots, number of canals per root and root canal configurations. Furthermore, the effect of gender on the canal variation was investigated.

Every specimen was analyzed in multiple sections and all three dimensions to accurately assess the internal anatomy of the root canal systems using Vertucci's classification. The observers evaluated the images twice with one-week interval between assessments.

\section{Statistical analysis of the data}

Data were fed to the computer and analyzed using IBM SPSS software package version 20.0. (Armonk, NY: IBM Corp). Comparisons between groups for categorical variables were assessed using Chi-square test (Monte Carlo). Significance of the obtained results was judged at the 5\% level.

\section{RESULTS}

A total of 600 mandibular anterior teeth were examined (200 central incisors, 200 lateral incisors, and 200 canines). The canal configurations of mandibular central were type I (Fig. 1), type III (Fig. 2) and type V (Fig. 3, 4) according to Vertucci's classification. Similarly, lateral incisors were found to be type I (Fig. 5), type III (Fig. 6, 7, 8), and type $\mathrm{V}$ (Fig. 9). While all the canines were only of Type I (Fig. 10, 11). Axial section showed a single apical foramen in all mandibular anterior teeth type I. (Fig. 12). The axial section showed the presence of two apical foramina in left central and lateral incisors and right lateral incisor (type V). (Fig. 13)

As shown in table (1): For female patients 95\% of central incisors were class I while $5 \%$ were class III compared to $76 \%$ class I, $17 \%$ class II and $7 \%$ class $\mathrm{V}$ in male patients. No canals were found with class II or IV in our sample for both female and male patients. Significant difference existed between male and female groups concerning root canal variations in central incisors. Regarding lateral incisors $91 \%$ was class I and $9 \%$ was class III in female patients, while $88 \%$ were class I, $7 \%$ class II and $5 \%$ class $\mathrm{V}$ in the male patients. Again no class II or IV were found in female or male samples. The difference in root canal variations in lateral incisors was insignificant between male and female groups. The configuration of mandibular canine was $100 \%$ type I in both female and male samples. Significant difference existed between root canal variations in central, lateral and canines within male or female group. 
TABLE (1): Comparison between different parameters according to Vertucci's classification.

\begin{tabular}{|c|c|c|c|c|c|c|c|c|}
\hline \multirow[b]{2}{*}{ Class } & \multicolumn{2}{|c|}{ Central } & \multicolumn{2}{|c|}{ Lateral } & \multicolumn{2}{|c|}{ Canine } & \multirow[b]{2}{*}{$\mathbf{p}_{1}$} & \multirow[b]{2}{*}{$\mathbf{p}_{2}$} \\
\hline & $\begin{array}{c}\text { Female } \\
(n=100)\end{array}$ & $\begin{array}{c}\text { Male } \\
(n=100)\end{array}$ & $\begin{array}{c}\text { Female } \\
(n=100)\end{array}$ & $\begin{array}{c}\text { Male } \\
(n=100)\end{array}$ & $\begin{array}{c}\text { Female } \\
(\mathrm{n}=100)\end{array}$ & $\begin{array}{c}\text { Male } \\
(\mathrm{n}=\mathbf{1 0 0})\end{array}$ & & \\
\hline I & $95(95 \%)$ & $76(76 \%)$ & $91(91 \%)$ & $88(88 \%)$ & $100(100 \%)$ & $100(100 \%)$ & $0.005^{*}$ & $<0.001^{*}$ \\
\hline II & $0(0 \%)$ & $0(0 \%)$ & $0(0 \%)$ & $0(0 \%)$ & 0 & $0(0 \%)$ & - & - \\
\hline III & $5(5 \%)$ & $17(17 \%)$ & $9(9 \%)$ & $7(7 \%)$ & 0 & $0(0 \%)$ & $0.005^{*}$ & $<0.001^{*}$ \\
\hline IV & $0(0 \%)$ & $0(0 \%)$ & $0(0 \%)$ & $0(0 \%)$ & 0 & $0(0 \%)$ & - & - \\
\hline V & $0(0 \%)$ & $7(7 \%)$ & $0(0 \%)$ & $5(5 \%)$ & 0 & $0(0 \%)$ & - & $0.023^{*}$ \\
\hline $\mathbf{P}$ & \multicolumn{2}{|c|}{$<0.001^{*}$} & \multicolumn{2}{|c|}{0.079} & \multicolumn{2}{|c|}{ - } & & \\
\hline
\end{tabular}

p: $p$ value for Chi square test for comparing between the Female and Male in each tooth

$p_{1}: p$ value for Chi square test for comparing between different teeth in Female

$p_{2}: p$ value for Chi square test for comparing between different teeth in Male

*: Statistically significant at $p \leq 0.05$

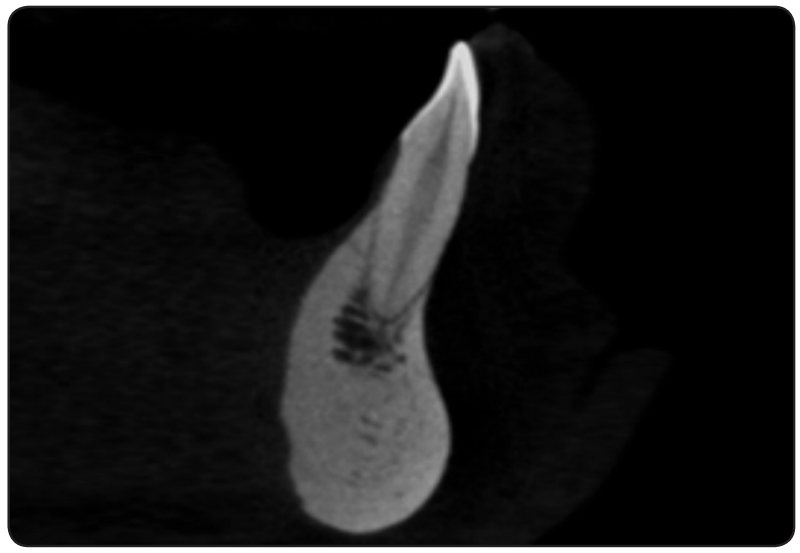

Fig. (1) Sagittal sections showing mandibular central incisor with one canal in single root (type I)

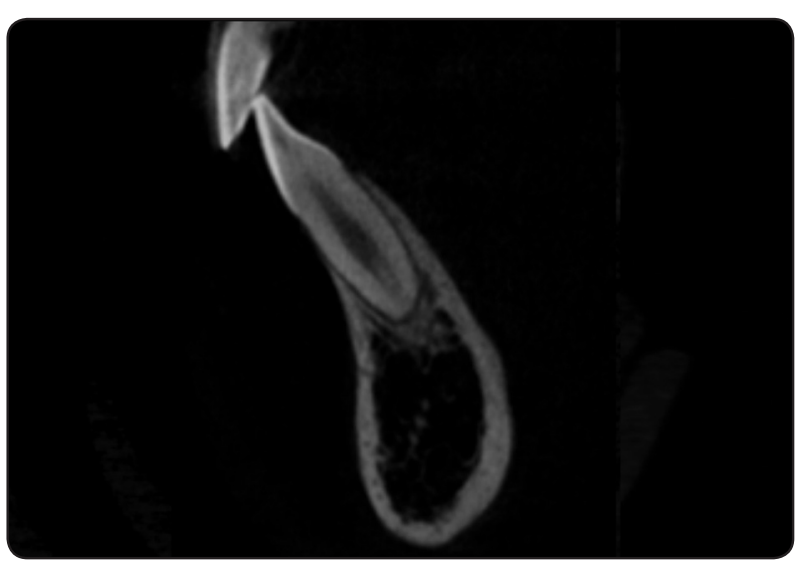

Fig. (3) Sagittal sections showing mandibular central incisor (type V)

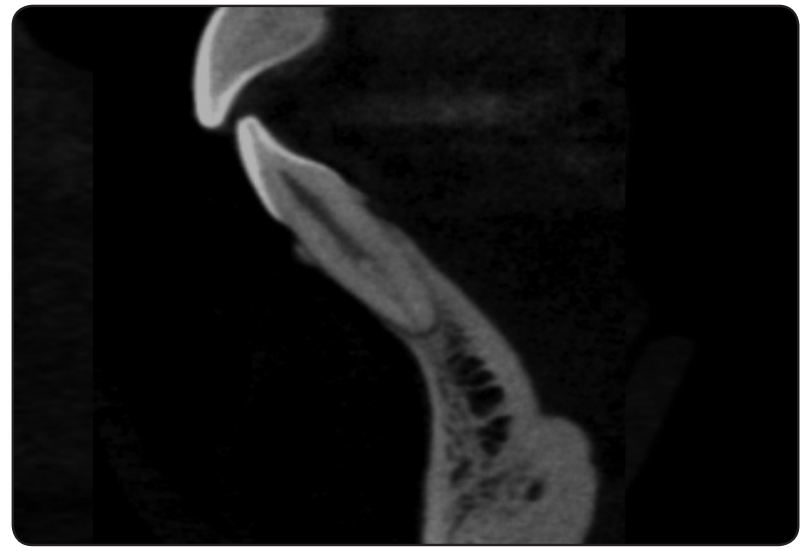

Fig. (2) Sagittal sections showing mandibular central incisor (type III)

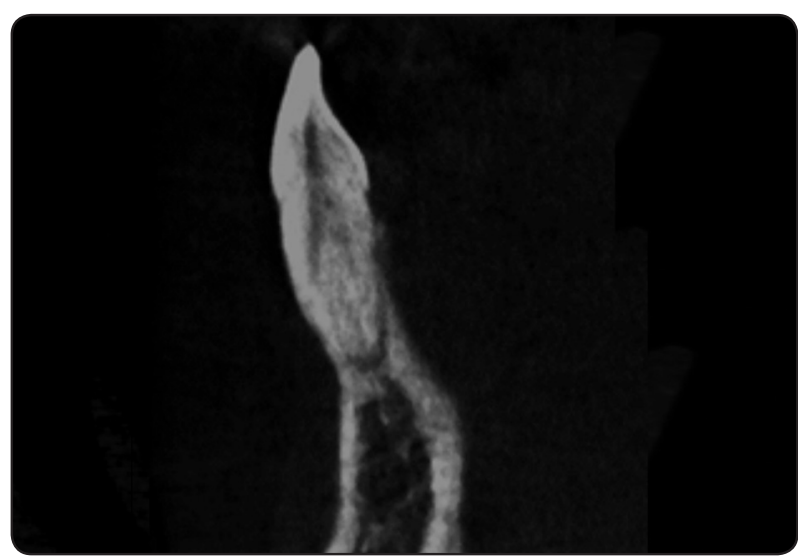

Fig. (4) Sagittal sections showing mandibular central incisor (type V) 


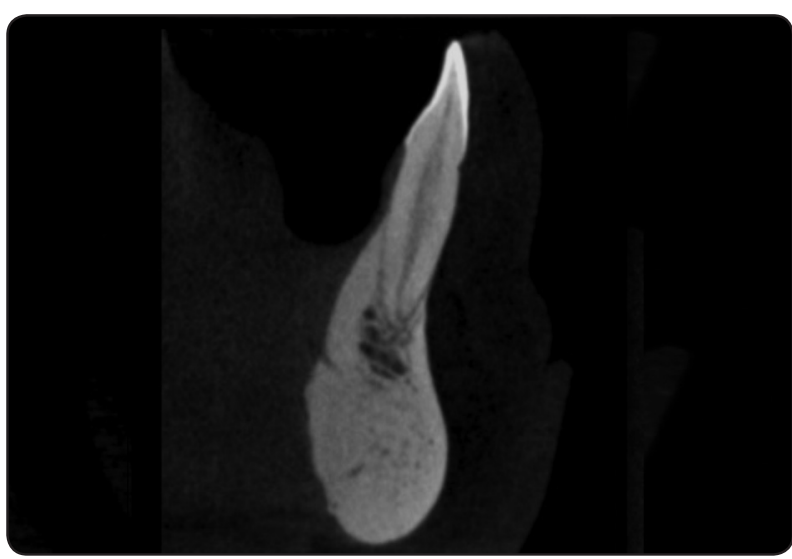

Fig. (5) Sagittal sections showing mandibular lateral incisor with one canal in single root (type I)

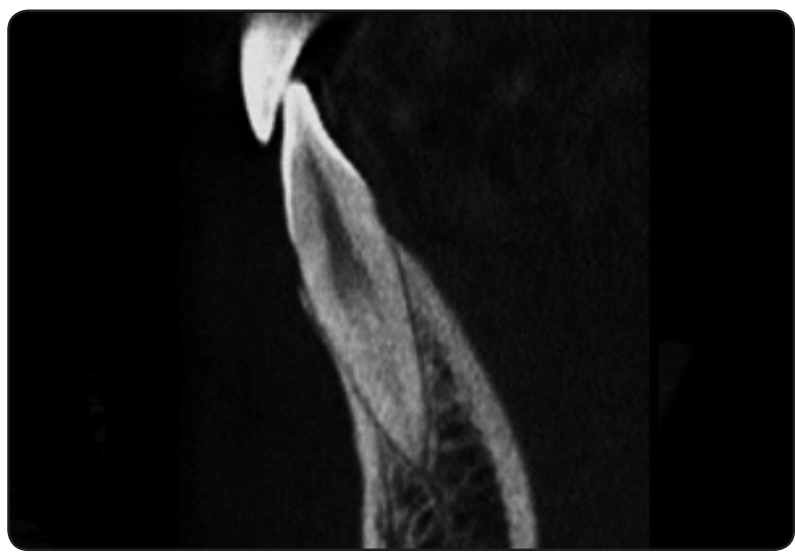

Fig. (7) Sagittal sections showing mandibular lateral incisor (type III)

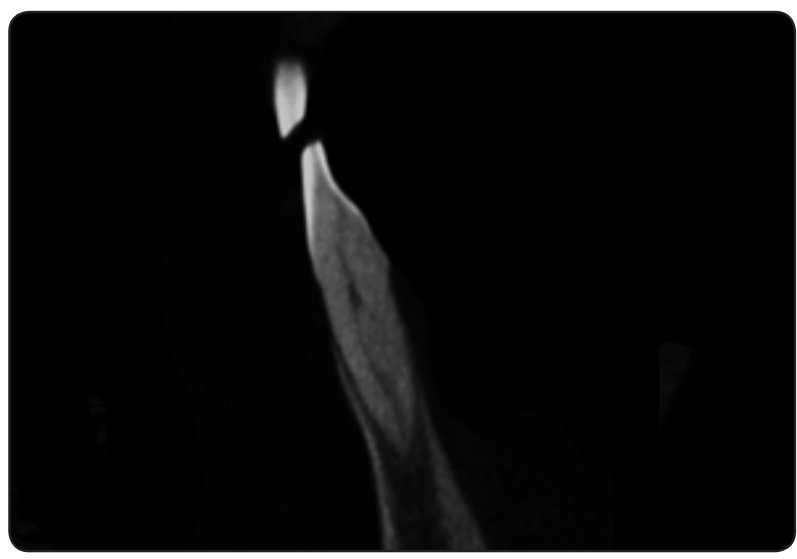

Fig. (9) Sagittal sections showing mandibular lateral incisor ( type V)

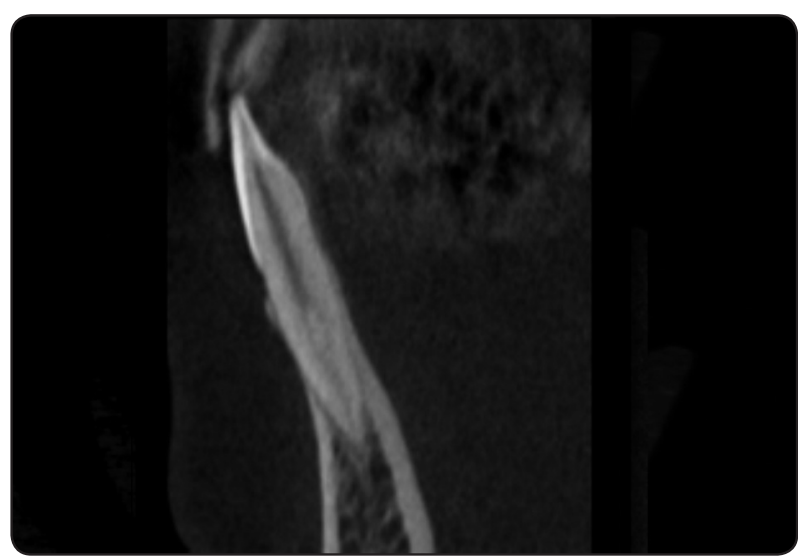

Fig. (6) Sagittal sections showing mandibular lateral incisor (type III)

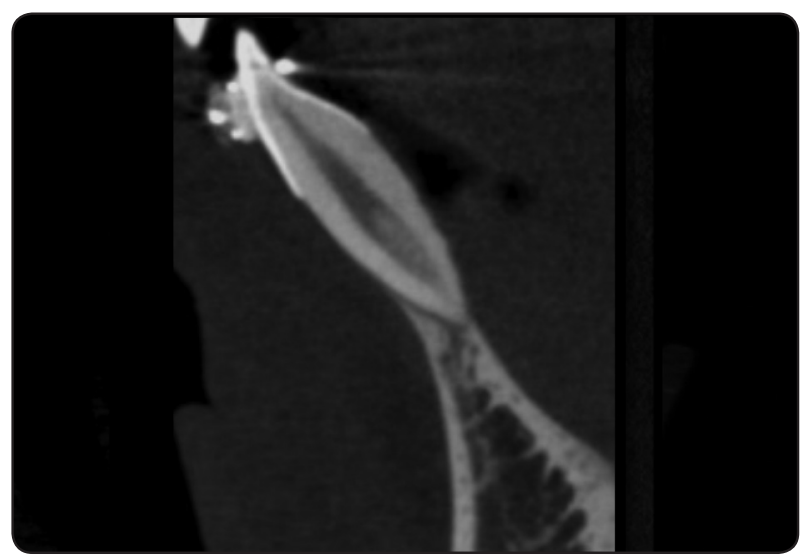

Fig. (8) Sagittal sections showing mandibular lateral incisor (type III)

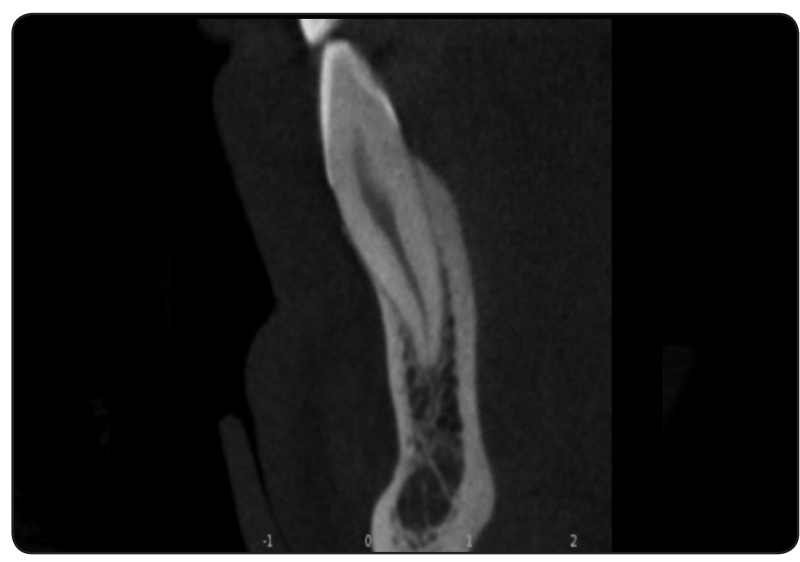

Fig. (10) Sagittal sections showing mandibular canine with one canal in single root (type I) 


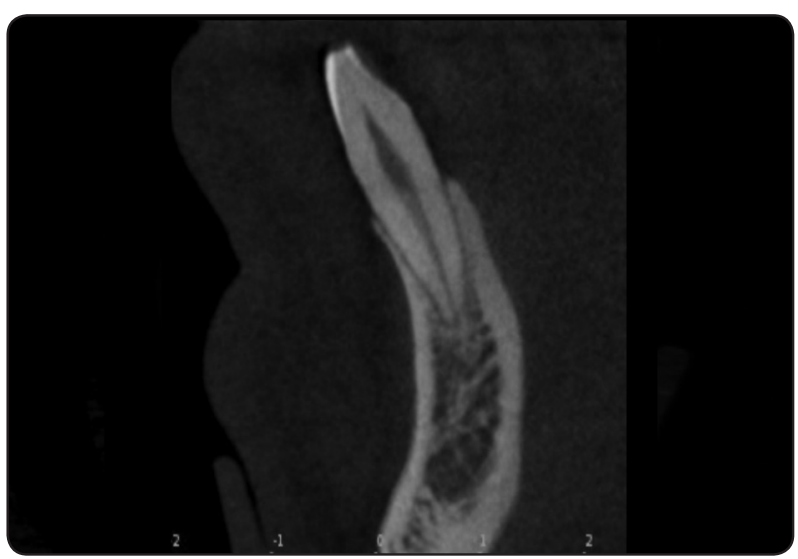

Fig. (11) Sagittal sections showing mandibular canine with one canal in single root (type I)

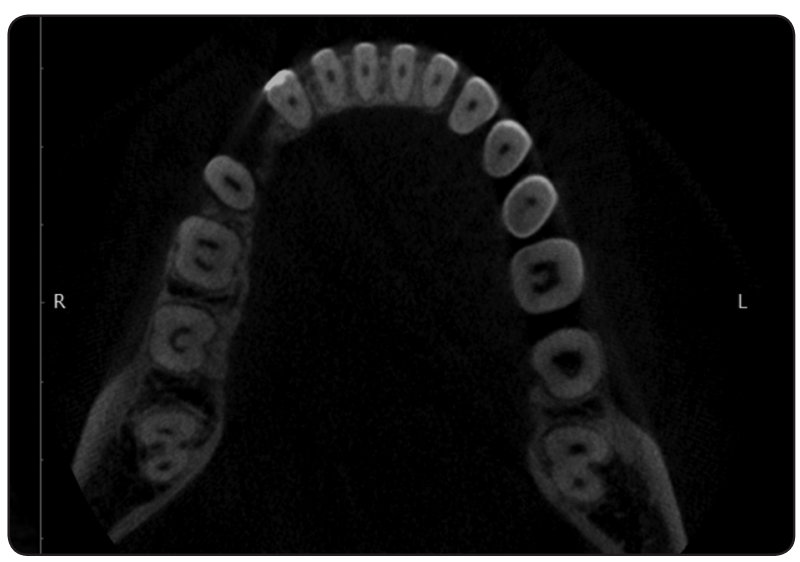

Fig. (12) Axial sections showing one apical foramen all mandibular anterior teeth. (type I)

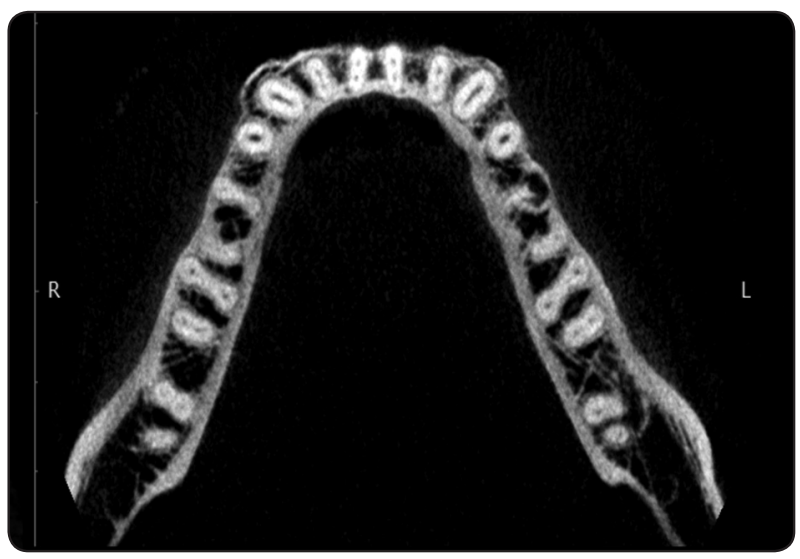

Fig. (13) Axial sections showing two apical foramina in left central and lateral incisors and right lateral incisor. (type V)

\section{DISCUSSION}

CBCT represent a significant advancement in dental and maxillofacial imaging as it offers numerous advantages compared to traditional 2D radiography. It has an important role in all dental specialties including endodontic field. Determination of root canal morphology plays a major role in endodontic successful treatment outcome. Inability to locate accessory canal, incomplete canal debridement and incomplete canal obturation are the main reasons for root canal failure. ${ }^{16}$

The current study aims to investigate the root canal anatomy and detect the probable variations in permanent mandibular anterior teeth (central, lateral and canine) of an Egyptian subpopulation, by means of CBCT.

In this study $100 \%$ of our samples had a single root for both male and female samples. In accordance, a study conducted on Indian population demonstrated that all the evaluated samples exhibited single root. ${ }^{7}$ Furthermore, these results were in agreement with Zhengyan et al. ${ }^{17}$ who conducted the study on Chongqing population and presented similar results concerning mandibular central incisors, while the authors concluded that $0.3 \%$ of the mandibular lateral incisors and $0.8 \%$ of mandibular canines had two roots.

Another study which was conducted on Chinese population revealed that all of the incisors in this study had one root, and $1.32 \%$ of the canines had two roots. ${ }^{18}$ Furthermore, a study by Aminsobhani et al. ${ }^{19}$ showed that the incidence of single rooted mandibular canines was $96.3 \%$ and the incidence of two rooted mandibular canines was $4.7 \%$ in the Iranian population.

Many studies ${ }^{9,20,21}$ concluded that the mandibular anterior teeth are almost always single rooted but the internal root canal anatomy is prone to exhibit complex variations. No data are available on the root canal morphology of mandibular incisors in Egyptian population. 
In our study type I Vertucci classification (single canal) was found in $95 \%$ and $76 \%$ of central incisors in females and males respectively and in $91 \%$ and $88 \%$ of lateral incisors in females and males respectively with slightly higher percentage in female than male samples. In agreement, studies on Turkish , Iranian and North-East Indian populations a have pointed out that single canal is the most common type of canal classification ${ }^{19,20,22}$

On the other hand, Prita et al. et al. ${ }^{7}$ conducted a study on Indian population on 200 central and lateral incisors and they found that $57 \%$ of mandibular central incisors and 54\% of mandibular lateral incisors presented with a single canal. That means almost half (43\% central and $46 \%$ lateral) of the specimens collected from an Indian population showed a second canal. Accordingly, the practitioners should have an adequate knowledge regarding these variations because understanding the root canal morphology is an important factor for successful endodontic treatment. ${ }^{23}$

Moreover, Estrela et al. ${ }^{24}$ who conducted a study on Brazilian population, demonstrated that two root canals were identified in $35 \%, 42 \%$ and $22 \%$ of mandibular central, lateral incisors and canines respectively.

In our study the prevalence of two root canal was higher in lateral incisors compared to central incisors. This was in accordance with Han et al. ${ }^{18}$ who demonstrated that the prevalence of two root canals in the lateral incisors $(27.36 \%)$ was higher than that in the central incisors $(15.71 \%)$ and the canines $(6.27 \%)$.

Additionally, Aminsobhani et al. ${ }^{19}$ pointed out that Type I Vertucci configuration was the most prevalent configuration in their sample $72.7 \%$, $70.6 \%$ and $71.8 \%$ for the central, lateral incisors and canines respectively. The results of the current investigation revealed that all our canine sample in both male and female populations were single rooted with type I Vertucci configuration.
Concerning type II Vertucci configuration, this type was not found in our sample. The same result was obtained by Al-Fouzan et al. ${ }^{25}$ who stated that type II was not found in Saudi Arabian sample of extracted mandibular incisors. However, in Palestinian ${ }^{26}$ population type II was found in $16.3 \%$ cases. In addition, a study of mandibular incisors in Indian population showed that $12 \%$ of central incisor canals and $15 \%$ of lateral incisor canals were type II Vertucci. ${ }^{21}$

In the present study $5 \%$ of central incisors and $9 \%$ of lateral incisors were type III for females compared to $17 \%$ and $7 \%$ in male sample. The result denoted a slightly higher percentage of type II in male sample in agreement with Liu et al. ${ }^{27}$ in which the percentage of incidence of a second canal was slightly higher in males $(14.6 \%)$ than in females (11.9\%)

In relation to Indian population Verma et al. ${ }^{21}$ demonstrated that $(15.25 \%)$ of their sample were Type-III Vertucci configuration. However, AlFouzan et al. ${ }^{25}$ demonstrated that $30 \%$ of mandibular central and lateral incisors were classified as type III. In addition, Mukhaimer et al. ${ }^{26}$ concluded that $29.3 \%$ of the mandibular incisors possessed a second root canal (Type II and III Vertucci configuration).

In the current study, Type IV Vertucci configuration was not found. The same result was obtained in many other studies ${ }^{24,25,26}$. Though, Verma et al. ${ }^{21}$ found that $2.37 \%$ of their sample showed Type IV. Furthermore, Prita et al. ${ }^{7}$ found $4 \%, 2 \%$ of central and lateral incisors showed type IV respectively.

The percentage of type $\mathrm{V}$ in the present study was $7 \%$ for central and 5\% for lateral incisors in male samples only, while in female samples type $\mathrm{V}$ was not found in neither centrals nor in laterals. Furthermore, type V Vertucci canal configuration was the least prevalent type seen in our sample. In agreement with Aminsobhani et al. ${ }^{19}$ who found that the least prevalent Vertucci's canal configuration was type $\mathrm{V}(3.6 \%, 3.2 \%$ and for central and lateral respectively). Whereas, type $\mathrm{V}$ was not found 
in Saudi Arabian ${ }^{25}$, Jordanian ${ }^{28}$ or Palestinian ${ }^{26}$ populations.

In the present study the effect of gender on the canal configuration was also investigated. The results demonstrated that more types were found in male group. These results were confirmed by Liu et al. ${ }^{27}$ and Zhengyan et al, ${ }^{17}$ they found that there was slightly higher percentage of incidence of a second canal in males.

According to the results of the current study, the incidence of canal variations might occur as a result of ethnicity more than gender. Consequently, more research considering these interfering factors are required.

\section{CONCLUSION}

From our study we concluded that the root and root canal morphology of Egyptian subpopulation was, in general, comparable to that of other populations. Additionally, type I Vertucci configuration was the most prevalent configuration in our sample and the incidence of this type was slightly higher in females than males samples. Furthermore, type III and V Vertucci configuration were slightly more in males than females. Finally, CBCT is an effective tool for determining the canal configuration.

\section{REFERENCES}

1. Creanga AG, Geha H, Sankar V, Teixeira FB, McMahan CA, Noujeim M. Accuracy of digital periapical radiography and cone-beam computed tomography in detecting external root resorption. Imaging Sci Dent. 2015;45(3):153-158.

2. Bhatia S, Kohli S. Cone-beam computed tomography usage: An alert to the field of dentistry. Imaging Sci Dent. 2016;46(2):145-146.

3. Abella F, Morales K, Garrido I, Pascual J, Duran-Sindreu F, Roig M. Endodontic applications of cone beam computed tomography: Case series and literature review. J Ital Endod. 2015;29(2):38-50.

4. Tetradis S, Anstey P, Graff-Radford S. Cone beam computed tomography in the diagnosis of dental disease. J Calif Dent Assoc. 2010;38(1):27-32
5. Jayasimha Raj U, Mylswamy S. Root canal morphology of maxillary second premolars in an Indian population. $\mathrm{J}$ Conserv Dent. 2010; 13: 148-151.

6. Kottoor J, Albuquerque D, Velmurugan N, Kuruvilla J. Root anatomy and root canal configuration of human permanent mandibular premolar: Asystematic review. Anat Res Int. 2013;2013: 14 pages.

7. Prita D, Ajinkya MP, Prashant S, Kulvinder B. An In-Vitro Cone-Beam Computed Tomographic Evaluation of Root Canal Anatomy of Permanent Mandibular Incisor Teeth in an Indian Population. Clin Radiol Imaging J. 2017; 1(2): 000108 (8pages).

8. Rahimi S, Milani AS, Shahi S, Sergiz Y, Nezafati S, Lotfi M. Prevalence of two root canals in human mandibular anterior teeth in an Iranian population. Indian J Dent Res, 2013; 24(2): 234-236.

9. Kamtane S, Ghodke M. Morphology of Mandibular Incisors: A Study on CBCT Pol J Radiol. 2016; 81: 15-16

10. Kayaoglu G, Peker I, Gumusok M, Sarikir C, Kayadugun A, Ucok O. Root and canal symmetry in the mandibular anterior teeth of patients attending a dental clinic: CBCT study. Braz Oral Res. 2015;29(1):1-7.

11. Domark JD, Hatton JF, Benison RP, Hildebolt CF. An Ex Vivo Comparison of Digital Radiography, Cone Beam and Micro Computed Tomography in the Detection of the Number of Canals in the Mesiobuccal Roots of Maxillary Molars. J Endod. 2013;39(7):901-905.

12. Wolf TG, Paqué F, Anja-Christin WoopAC, Willershausen B, Briseño-Marroquín B. Root canal morphology and configuration of 123 maxillary second molars by means of micro-CT. Int J Oral Sci. 2017; 9(1): 33-37.

13. Lin YH, Lin HN, Chen CC, Chen MS. Evaluation of the root and canal systems of maxillary molars in Taiwanese patients: A cone beam computed tomography study. Biomed J. 2017;40(4):232-238.

14. Meena N, Kowsky RD. Applications of Cone Beam Computed Tomography in Endodontics: A Review. Dentistry 2014; 4(7):1-9.

15. Vertucci FJ. Root canal anatomy of the human permanent teeth. Oral Surg, 1984;58:589-599.

16. Tabassum S, Khan FR. Failure of endodontic treatment: The usual suspects. Eur J Dent. 2016;10(1):144-147.

17. Zhengyan Y, Keke L, Fei W, Yueheng L, Zhi Z. Conebeam computed tomography study of the root and canal morphology of mandibular permanent anterior teeth 
in a Chongqing population. Ther Clin Risk Manag. 2016;12:19-25.

18. Han T, Ma Y, Yang L, Chen X, Zhang X, Wang Y. A study of the root canal morphology of mandibular anterior teeth using cone-beam computed tomography in a Chinese subpopulation. J Endod. 2014;40(9):1309-1314.

19. Aminsobhani M, Sadegh M, Meraji N, Razmi H, Kharazifard MJ. Evaluation of the Root and Canal Morphology of Mandibular Permanent Anterior Teeth in an Iranian Population by Cone-Beam Computed Tomography. J Dent (Tehran). 2013;10(4):358-366.

20. Geduk G, Deniz Y, Zengin AZ, Eroglu E. Cone-beam computed tomography study of root canal morphology of permanent mandibular incisors in a Turkish sub-population. $\mathrm{J}$ Oral Maxillofac Radiol. 2015;3:7-10.

21. Verma GR, Bhadage C, Bhoosreddy AR, Vedpathak PR, Mehrotra GP, Nerkar AC, Bhandari A, Chaubey S. Cone Beam Computed Tomography Study of Root Canal Morphology of Permanent Mandibular Incisors in Indian Subpopulation. Pol J Radiol. 2017;82:371-375.

22. Boruah LC, Bhuyan AC. Morphologic characteristics of root canal of mandibular incisors in North-East
Indian population: An in vitro study. J Conserv Dent. 2011;14(4):346-350.

23. Daokar SG, Kalekar (Yadao) AS, Ghunawat DB, KakdeDD. All the Mandibular Incisors with Double Canals in a Single Patient: A Rare Case. J Int Oral Health.2015;7(2):46-49.

24. Estrela C, Bueno MR, Couto GS, Rabelo LE, Alencar AH, Silva RG, Pécora JD, Sousa-Neto MD. Study of Root Canal Anatomy in Human Permanent Teeth in A Subpopulation of Brazil's Center Region Using Cone-Beam Computed Tomography - Part 1. Braz Dent J. 2015; 26(5): 530-536.

25. Al-Fouzan KS, AlManee A, Jan J, Al-Rejaie M. Incidence of two canals in extracted mandibular incisors teeth of Saudi Arabian samples. Saudi Endod J. 2012;2:65-69.

26. Mukhaime R, Jarbawi M. Radiographic study of the root canal system of mandibular incisors in Palestinian population. OJST. 2013, 3, 452-456.

27. Liu J, Luo J, Dou L, Yang D. CBCT study of root and canal morphology of permanent mandibular incisors in a Chinese population. Acta Odontol Scand. 2014;72(1):26-30.

28. Al-Qudah AA, Awawdeh LA. Root canal morphology of mandibular incisors in a Jordanian population. Int Endod J. 2006; 39(11): 873-877. 